DOI: https://doi.org/10.24127/ajpm.v9i4.3162

\title{
PENGEMBANGAN INSTRUMEN PENGUKUR HIGHER ORDER THINKING SKILLS (HOTS) MATEMATIKA PADA SISWA SEKOLAH MENENGAH PERTAMA
}

\author{
Eka Rachma Kurniasi $^{*}$, Ayen Arsisari ${ }^{2}$ \\ ${ }^{1 *}, 2$ Pendidikan Matematika, Universitas Muhammadiyah Bangka Belitung, \\ Pangkalpinang, Indonesia \\ *Corresponding author \\ E-mail: $\quad \underline{\text { eka.rachmakurniasi@stkipmbb.ac.id }}^{\left.1^{*}\right)}$ \\ ayen.arsisari@stkipmbb.ac.id $^{21}$
}

Received 18 October 2020; Received in revised form 07 December 2020; Accepted 29 December 2020

\begin{abstract}
Abstrak
Latar belakang penelitian adalah kurangnya soal-soal Higher Order Thinking Skills (HOTS) yang tersedia, siswa masih kurang dilatih mengerjakan soal HOTS, dan guru belum sepenuhnya memahami pengembangan soal-soal HOTS padahal dalam upaya peningkatan kemampuan HOTS siswa perlu dibiasakan menghadapi soal-soal HOTS. Penelitian ini bertujuan untuk mengembangan instrumen pengukur HOTS matematika bagi siswa Sekolah Menengah Pertama(SMP) kelas VII semester satu. Metode penelitian adalah penelitian dan pengembangan dengan tahapan ADDIE yaitu analisis, desain, pengembangan, implementasi, dan evaluasi. Instrumen yang digunakan dalam penelitian adalah soal tes HOTS berbentuk uraian, lembar observasi, angket respon, dan lembar wawancara. Adapun alur penelitian dimulai dengan analisis awal, pengembangan kisi-kisi soal HOTS, validasi ahli, revisi, uji praktisi, uji coba skala kecil, revisi, dan uji coba skala besar. Hasil penelitian adalah 18 butir soal HOTS dengan Standar Kompetensi Bilangan, Himpunan, Aljabar, dan Sistem Persamaan Linier Dua Variabel. Indikator instrumen HOTS yang dikembangkan meliputi kemampuan analisis, evaluasi, dan kreasi. Soal yang dikembangkan mempunyai kualitas valid dilihat dari uji validitas butir soal semua diatas 0,5 , reliabilitas 0,86, tingkat kesukaran sulit dan sedang, serta daya pembeda baik dan cukup. Adapun skor rerata HOTS siswa adalah 71. Kesimpulan dari penelitian ini adalah menghasilkan instrumen pengukur HOTS siswa sekolah menengah pertama yang valid dan reliabel.
\end{abstract}

Kata Kunci : HOTS; Matematika; SMP

\begin{abstract}
The research background is the lack of available HOTS questions, students are still not trained to work on HOTS questions, and teachers do not fully understand the development of HOTS questions, even though in an effort to improve students' HOTS abilities, they need to be accustomed to dealing with HOTS questions. This study aims to develop an instrument for measuring Mathematics Higher Order Thinking Skills (HOTS) for seventh grade junior high school students in the first semester. The research method is research and development with ADDIE stages, namely analysis, design, development, implementation and evaluation. The instruments used in the study were HOTS test questions in the form of descriptions, observation sheets, response questionnaires, and interview sheets. The research flow begins with the initial analysis, development of a HOTS question grid, expert validation, revision, practitioner testing, small-scale trials, revisions, and large-scale trials. The results of the study were 18 HOTS items with Competency Standards for Numbers, Sets, Algebra, and Two-Variable Linear Equation System. The HOTS instrument indicators developed include analytical, evaluation, and creative abilities. The questions developed have valid quality seen from the validity test of all items above 0.5, 0.86 reliability, difficult and moderate difficulty levels, as well as good and sufficient distinguishing power.The average HOTS score of the students was 71.The conclusion of this study is to produce a valid and reliable HOTS measuring instrument for junior high school students.
\end{abstract}

Keywords: HOTS; Junior High School; mathematic

This is an open access article under the Creative Commons Attribution 4.0 International License 


\section{PENDAHULUAN}

Matematika sebagai salah satu mata pelajaran yang memang konsen dalam upaya mengasilkan SDM dengan tingkat kognitif yang baik. Salah satu kemampuan yang disebut sangat penting oleh Menteri Pendidikan adalah kemampuan berpikir tingkat tinggi (higher order thinking skills). Urgensi dari pengembangan HOTS ditunjukkan dari hasil penelitian bahwa HOTS adalah tujuan utama dalam pendidikan dan menjadi salah satu dari lima variabel teratas yang dapat meningkatkan prestasi belajar siswa (Pratama \& Retnawati, 2018).

HOTS adalah keterampilan berpikir mulai tahap mengevaluasi gagasan sampai pada pengambilan keputusan dan melakukan pemilihan ide keputusan (Prayitno, Suciyati, \& Kusumawardani, 2018). HOTS mempunyai ciri khusus adalah bersifat nonalgoritmik, bersifat kompleks, mempunyai banyak solusi, melibatkan variasipengambilan keputusan dan interpretasi, penerapan banyak kriteria, dan bersifat effortful (Budiman \& Jailani, 2014).

Beberapa penelitian menuliskan definisi HOTS bahwa HOTS merupakan suatu proses internal yang terjadi di dalam diri seseorang yang ditandai oleh beberapa karakteristik sebagai berikut: (1) Melibatkan lebih dari satu jawaban benar; (2) Berbicara tentang tingkat pemahaman; (3) Ditandai dengan tugas yang kompleks; dan (4) Bebas konten dan sekaligus content-related, Astutik, (Zaini, 2015). Begitu pentingnya proses berpikr tingkat tinggi, sehingga ada teori yang menyatakan bahwa terdapat korelasi positif antara keterampilan berpikir tingkat tinggi siswa dengan prestasi belajar mereka (Tanujaya, Mumu, \& Margono, 2017).
Beberapa penelitian terdahulu mengenai HOTS yaitu (1) Arifin dan Retnawati (2017) yang meneliti tentang pengembangan instrumen pengukur HOTS siswa SMA; (2) Ahmad, Kenedi, dan Maslinadevi (2018) yang mengembangan instrumen HOTS matematika bagi mahasiswa PGSD; (3) Hanifah (2019) yang mengembangkan instrumen HOTS bagi siswa SD. Sedangkan penelitian ini mengembangkan instrumen pengukur HOTS siswa SMP.

Aspek menganalisis adalah kemampuan memisahkan beberapa materi menjadi hal yang lebih kecil atau bagian-bagian yang kemudian ditentukan bagaimana setiap bagian itu saling berhubungan. Aspek evaluasi adalah kemampuan dalam pengambilan keputusan, mampu mengutarakan pendapat, atau menilai berdasarkan kriteria dan standar tertentu. Sedangkan pada aspek kreasi siswa mampu menghasilkan gagasan baru dalam materi tersebut (Prayitno, Suciyati, \& Kusumawardani, 2018). Padahal kemampuan berpikir tingkat tinggi siswa hanya dapat berkembang dengan baik jika siswa dibiasakan dengan aktivitas yang melatih HOTS. Aktivitas tersebut tidak hanya dengan pemberian materi, penting pula menyiapkan alat evaluasi untuk mengukur HOTS. Menyiapkan alat ukur yang tepat untuk mempersiapkan siswa memiliki kemampuan berpikir tingkat tinggi merupakan sebuah keharusan tidak hanya memalui aktivitas pembelajaran (Sa'idah, Yulistiani, \& Megawati, 2019). Menggunakan model pembelajaran yang tepat dan soal-soal latihan HOTS dapat meningkatkan kemampuan HOTS siswa (Arifin \& Retnawati, 2017). Berdasarkan hal tersebut tentunya guru perlu menyiapkan instrumen yang tepat agar 
dapat mempersiapkan siswa dalam berpikir HOTS berupa soal-soal yang digunakan untuk mengukur HOTS siswa.

Namun beberapa hasil penelitian mengungkapkan bahwa kemampuan berpikir tingkat tinggi siswa Indonesia masih rendah. Berdasarkan data hasil survey TIMSS tahun 2015 peringkat Indonesia 44 dari 49 negara dengan rerata skor 397 (TIMSS,2015). Hal ini disebabkan kurangnya siswa-siswa dilatih dengan soal-soal matematika dengan tingkatan HOTS. Hasil ini sejalan dengan penelitian Thomson (Budiman \& Jailani, 2014) bahwa guru menghadapi masalah dalam mengembangkan instrumen HOTS. Ketersediaan instrumen berbentuk HOTS pun masih belum banyak, sehingga tidak banyak referensi yang dapat digunakan untuk melatih siswa. Terdapat 32 orang guru matematika yang diteliti mengalami kesulitan menafsirkan keterampilan berpikir dalam Taksonomi Bloom dan membuat item tes untuk berpikir tingkat tinggi.

Hasil wawancara dengan salah satu guru matematika SMP negeri di Kota Pangkalpinang menyatakan, tidak setiap hari dia memberikan soal-soal HOTS kepada siswa. Soal-soal HOTS yang dia berikan adalah hasil pengembangannya sendiri, namun memang dirasa sulit jika hanya sendiri dalam mengembangkan soal-soal HOTS tersebut. Hasil observasi beberapa SMP di Kota Pangkalpinang menyatakan guru masih mengambil soal-soal yang tersedia pada buku paket yang beberapa hanya mengukur kemampuan tingkat rendah. Hal ini terjadi karena guru mengalami masalah dalam mengembang-kan instrumen yang mengukur kemampuan HOTS selain itu ketersediaan instrumen yang didesain khusus untuk melatih aktivitas HOTS juga belum banyak (Kurniasi, Yopa, \& Karennisa, 2020).

Berdasarkan hal tersebut maka dilakukan kajian dan penelitian mengenai pengembangan instrumen pengukur High Order Thinking Skill (HOTS) matematika pada siswa SMP Kelas VII semeter 1. Penting mengetahui sejauh mana kemampuan siswa perlu sebuah instrumen tepat untuk mengukurnya, selain itu diperlukan untuk latihan kemampuan HOTS.

\section{METODE PENELITIAN}

Jenis penelitian ini adalah penelitian pengembangan (Research and Development). Langkah-langkah dalam membuat penelitian ini dilakukan dengan model pengembangan ADDIE yangdikembangkan Dick and Carry dengan tahapan (Analysis, Design, Development or Production, Implementation or Delivery and Evaluations) (Branch, 2009)

Adapun alur penelitian mencakup lima tahapan berdasarkan metode ADDIE digambarkan dalam Gambar 1.

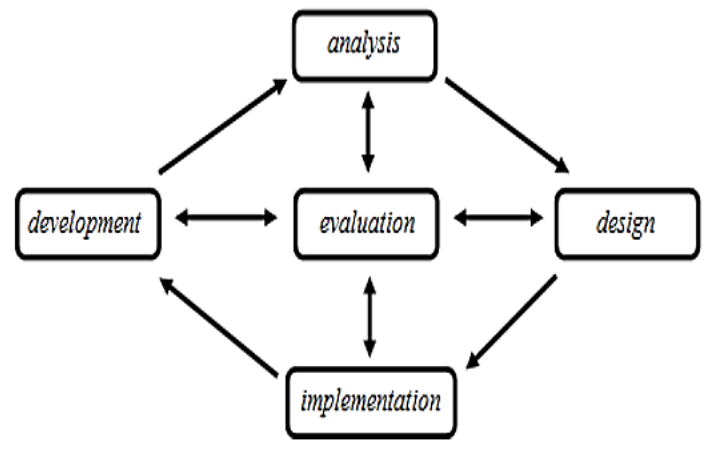

Gambar 1. Metode penelitian ADDIE.

Tahap pertama analisis kebutuhan dilakukan untuk mengetahui apakah pengembangan instrumen HOTS perlu dilakukan. Studi pendahuluan dilaksana-kan di SMP Kelas 7 Semester Ganjil Tahun ajaran 
2019/2020 Kota Pangkalpinang. Berdasarkan analisis kebutuhan disimpulkan bahwa dibutuhkan instrumen pengukur HOTS matematika bagi siswa SMP kelas VII. Kemudian analisis materi, kegiatan ini berpedoman pada kompetensi inti dan kompetensi dasar yang akan dijadikan sebagai dasar pembuatan butir soal instrumen tes HOTS. Pada analisis materi ini, dipilih materi pada pelajaran matematika untuk mengetahuikemampuan siswa dalam pengerjaan soal-soal HOTS yaitu materi Bilangan, Himpunan, Aljabar, dan Sistem Persamaan Linier Satu Variabel.

$$
\text { Tahap kedua Design }
$$

(Perancangan), tahap ini adalah desain produk. Pada tahap ini peneliti membuat kisi-kisi butir soal yang mencakup indikator HOTS yaitu analisis, evaluasi, dan kreasi untuk setiap materi. Adapun total jumlah soal adalah 18 soal berbentuk uraian, dengan setiap soal mengandung tiga indikator HOTS.

Tahap ketiga Development (Pengembangan) yaitu pengembangan produk pembuatan instrumen tes HOTS, pada tahapan ini akan dilakukan; Validasi teori dan konstruks; reliablitas soal, revisi soal, Revisi desain, Produk Akhir. Adapun validasi ahli mencakup dua orang ahli evaluasi pembelajaran matematika dan satu orang ahli materi matematika. Praktisi adalah guru $\begin{array}{lll}\text { matematika } & \text { SMPN } 7 \text { Kota }\end{array}$ Pangkalpinang.

Tahap keempat Implementation (Implementasi) pada tahap ini dilakukan uji coba produk instrumen tes HOTS. Uji coba kelompok kecil melibatkan 10 orang subjek yang berasal dari siswa kelas VIII SMPN 7 Kota Pangkalpinang. Uji coba kelompok besar melibatkan 30 siswa kelas VIII SMPN 7 Kota Pangkalpinang.

Tahap trakhir adalah Evaluation (Evaluasi) Evaluasi dilakukan setiap tahap penelitian mulai dari rancangan penilaian, pembuatan produk, validasi desain, revisi. Subjek dalam penelitian ini adalah siswa kelas VIII SMPN 7 Kota Pangkalpinang yang berasal dari 3 kelas berbeda, Instrumen yang digunakan dalam pengumpulan data pada penelitian ini adalah: Lembar validasi tim ahli; Lembar angket praktisi (guru); Lembar angket persepsisiswa; Lembar Observasi; Lembar wawancara; Instrumen tes HOTS berbentuk uraian. Analisis data yang dilakukan pada instrumen pengumpulan data adalah analisis soal, validitas butir soal, tingkat kesukaran, analisis daya beda, analisis reliabilitas soal tes, analisis data hasil angket ahli materi, analisis uji praktisi, analisis hasil uji skala kecil. Validasi instrumen pengukur HOTS diukur dengan menggunakan skala Likert lima skala, dengan tingkat valid 1-5. Skor yang telah diperoleh berdasarkan penilaian ahli kemudian diubah ke dalam persentase. Persentase ini dihitung dengan menggunakan rumus (1):

$$
V=\frac{\sum x}{\sum x i} \times 100 \%
$$

Adapun keterangan rumus (1) adalah $V$ persentase validitas instrumen, $\Sigma x$ adalah jumlah keseluruhan penilaian ahli, dan $\Sigma x i$ adalah jumlah keseluruhan nilai ideal. Setelah hasil persentase diketahui, tingkat validitas instrumen yang dikembangkan kemudian dikelompokkan ke dalam kriteria validitas produk yang ditunjukkan pada Tabel 1 .

Adapun untuk menghitung validitas butir soal instrumen HOTS menggunakan rumus Korelasi Product Moment dengan Angka Kasar. Adapun menghitung reliabilitas butir soal menggunakan rumus Cronbach-Alpha. 
DOI: https://doi.org/10.24127/ajpm.v9i4.3162

Tabel 1. Kriteria validitas ahli materi dan evaluasi pembelajaran matematika.

\begin{tabular}{lll}
\hline No & \multicolumn{1}{c}{$\begin{array}{c}\text { Kriteria } \\
\text { Validitas }\end{array}$} & \multicolumn{1}{c}{$\begin{array}{c}\text { Tingkat } \\
\text { Validitas }\end{array}$} \\
\hline 1 & $85 \%<V \leq 100 \%$ & Sangat valid \\
2 & $70 \%<V \leq 85 \%$ & Valid \\
3 & $50 \%<V \leq 70 \%$ & Kurang valid \\
4 & $V \leq 50 \%$ & Tidak valid \\
\hline
\end{tabular}

\section{HASIL DAN PEMBAHASAN}

Proses Pengembangan Instrumen

Pada tahap analisis didapat data bahwa instrumen Higher Order Thinking Skill (HOTS) belum ada dikembangkan oleh guru SMP. Selain itu tahap ini menghasilkan definisi HOTS yang akan dikembangkan instrumennya. Tahap desain menghasilkan desain awal instrumen HOTS.

Penelitian ini menghasilkan instrumen pengkur HOTS matematika kelas VII semester 1 dengan Standar Kompetensi Bilangan, Himpunan,
Aljabar, dan Sistem Persamaan Linier Satu Variabel. Adapun jumlah soal adalah 19 soal dengan bentuk instrumen tes uraian. Berdasarkan metode ADDIE maka desain awal divalidasi oleh tiga orang ahli yaitu ahli evaluasi pembelajaran matematika dan ahli materi matematika. Hasilnya menunjukkan bahwa instrumen layak digunakan dengan perbaikan. Adapun kriteria kevalidan instrumen HOTS berdasarkan ketiga ahli di analisis dengan rumus presentasi pada nomor (1). Hasilnya menunjukkan bahwa aspek validasi isi adalah $78 \%$, validasi konstruksi adalah 85\%, aspek validasi bahasa $80 \%$, alokasi waktu $74 \%$, dan instruksi soal $65 \%$. Berdasarkan kriteria validasi ahli pada Tabel 2, maka disimpulkan instrumen pengukur HOTS siswa valid, namun berdasarkan saran ahli ada beberapa perbaikan. Beberapa saran tersebut disajikan pada Tabel 2.

Tabel 2. Saran perbaikan instrumen HOTS dan para ahli

\section{Saran Perbaikan}

Tidak konsisten dalam penulisan ilustras soal.

Ilustrasi pada cerita dengan soal yang disajikan pada indikator menganalisis masih belum terlalu cocok

\section{Perbaikan}

Sebuah pabrik makanan instan kemasan akan membuat sosis. Para ahli gizinya mengukur suhu yang tepat untuk pembekuan daging yang terbaik sebagai bahan pembuat sosis. Jika semakin rendah suhu semakin baik dalam mempertahankan kualitas daging, maka urutkankalah suhu berikut mulai dari yang terbaik untuk pembekuan daging. $-12^{\circ}$, $12^{\circ},-15^{\circ},-30^{\circ}, 30^{\circ}, 15^{\circ}$

Berdasarkan cerita di nomor 1 di atas, jika untuk sosis merk A, daging beku sosis merk A setiap 2 menit suhu akan turun $5^{\circ}$. Sosis merk B daging beku sosis merk B setiap 4 menit turun $3^{\circ}$, dan sosis merk $\mathrm{C}$ daging beku sosis merk $\mathrm{C}$ setiap 5 menit turun $4^{\circ}$. Maka daging beku sosis merk mana yang yang paling tinggi penurunan suhunya jika dikeluarkan 20 menit? 
DOI: https://doi.org/10.24127/ajpm.v9i4.3162

Saran Perbaikan

Salah salam penulisan angka untuk nominal uang. Sebaiknya tidak memasukkan istilah di luar SK yang dijadikan instrumen.

Perbaikan

Berdasarkan cerita di soal nomor 3 sebelumnya, jika biaya yang dibutuhkan untuk membangun sebuah ruko adalah $\mathrm{Rp}$. 100.000.000 dan biaya sewa pertahun adalah Rp135.000.000. Sedangkan biaya sewa untuk tanah tanpa bangunan adalahRp 50.000.000 dan biaya sewa untuk arena pertahun adalah Rp35.000.000. Maka sewa mana yang lebih menguntungkan? Berikan alasanmu!

Setelah dilakukan perbaikan berdasarkan saran para validator, maka instrumen tes diberikan kepada guru matematika SMPN 7 Kota Pangkalpinang sebagai praktisi. Hasil berdasarkan persantase kevalidan menyatakan $82 \%$ tingkat kevalidan instrumen artinya instrumen valid. Terdapat beberapa perbaikan antara lain: (1). Petunjuk pengerjaan pada soal perlu diperbaiki untuk setiap SK; (2). Bila perlu tambahkan soal-soal yang mengandung unsur geometri sebagai pengait antar konsep. Kemudian berdasarkan saran dari praktisi dilakukan perbaikan dan kemudian dilakukan uji coba skala kecil dengan jumlah siswa 10 orang. Berasal dari siswa kelas VIII SMPN 7 Kota Pangkalpinang.

Hasil dari uji coba skala kecil adalah presentasi respon siswa sebesar $87 \%$ artinya instrumen sangat valid. Adapun berdasarkan wawancara kepada subjek menyatakan bahwa siswa paham dengan soal yang disajikan untuk setiap indikator. Siswa dapat mengerjakannya dengan baik. Diperlukan waktu yang cukup lama sekitar 4 jam untuk mengerjakan keseluruhan soal. Siswa merasa kesulitas pada soal dengan indikator kreasi. Petunjuk pengerjaan soal perlu diperbaiki. Bentuk soal benar salah akan lebih cepat dikerjakan siswa. Berdasarkan analisis didapatkan bahwa siswa mampu menjawab soal analisis dan evaluasi dengan baik, namun kurang lengkap dalam menjawab soal dengan indikator kreasi. Hasil jawaban siswa disajikan pada Gambar 3.

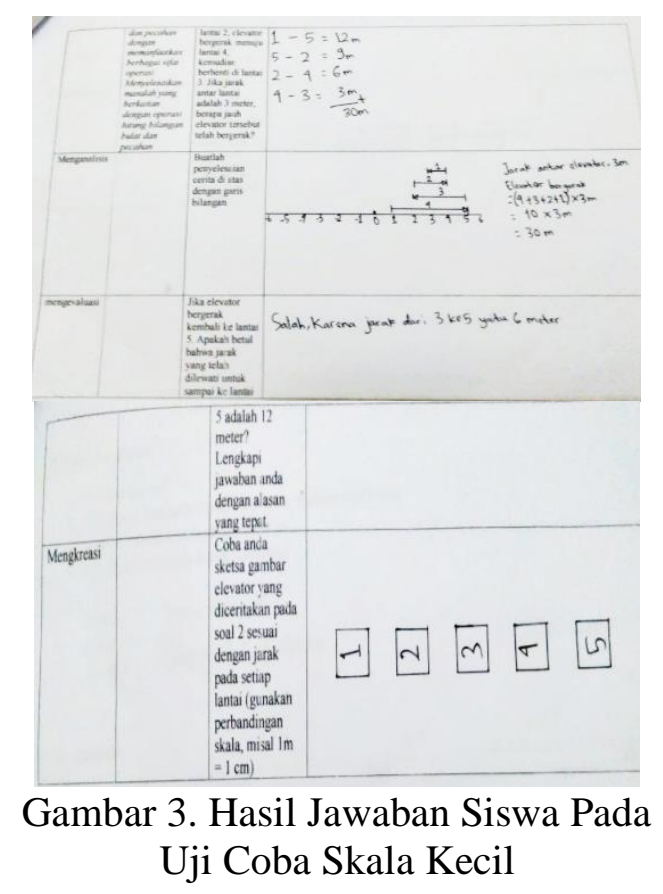

Hasil jawaban siswa menunjukkan bahwa siswa dapat menjawab sesuai dengan jawaban benar untuk soal dengan indikator menganalisis dan mengevaluasi. Namun siswa tidak dapat mensketsa elevator sesuai dengan skala yang diminta pada soal indikator kreasi. Adapun nilai rerata 10 orang siswa pada uji coba skala kecil adalah 71 dengan skala 1-100. Skor siswa pada uji coba instrumen pengukur HOTS disajikan pada Tabel 3. 
DOI: https://doi.org/10.24127/ajpm.v9i4.3162

Tabel 3. Skor uji coba skala kecil

\begin{tabular}{|c|c|}
\hline Siswa & Skor (Skala 100) \\
\hline $\mathrm{S} 1$ & 65 \\
\hline S2 & 75 \\
\hline S3 & 80 \\
\hline S4 & 60 \\
\hline S5 & 55 \\
\hline S6 & 90 \\
\hline S7 & 70 \\
\hline S8 & 80 \\
\hline S9 & 60 \\
\hline S10 & 75 \\
\hline Total & Rerata 71 \\
\hline
\end{tabular}

Berdasarkan Tabel 3. Bahwa nilai rerata siswa cukup baik pada uji coba skala kecil. Nilai rerata ini diangkap tuntas karena sudah mencapai KKM mata pelajaran matematika di SMPN 7 Kota Pangkalpinang yaitu 70. Selanjutnya berdasarkan hasil ujicoba skala kecil dilakukan revisi yang mencakup petunjuk pada soal serta variasi bentuk soal analisis dengan menceklis pernyataan benar atau salah.

Tahap selanjutnya setelah revisi hasil uji coba skala kecil dan uji praktisi adalah uji coba skala besar. Pada uji coba skala besar ini melibatkan 30 subjek yang berasal dari SMPN 7 Kota Pangkalpinang. Subjek yang dipilih adalah berbeda dengan subjek pada tahap uji coba skala kecil. Hasil dari uji coba skala besar adalah instrumen HOTS matematika siswa SMP kelas VII semester 1 yang telah diuji kualitasnya.

Perhitungan kualitas instrumen meliputi validitas konstruk, reliabilitas, daya pembeda, dan indeks kesukaran. Menghitung validitas konstruk digunakan analisis faktor eksploratori. Adapun interpretasinya adalah jika nilai KMO (Kaiser Meyer Olkin) lebih dari 0,5 maka instrumen valid (Arifin \& Retnawati, 2017). Adapun nilai KMO diperoleh melalui bantuan SPSS IBM 2.0. Berdasarkan perhitungan diperoleh bahwa kualitas instrumen HOTS matematika siswa SMP kelas VII semester satu meliputi validitas, reliabilitas, daya pembeda, dan indeks kesukaran yang dikembangkan disajikan pada Tabel 4 .

Tabel 4. Validitas, tingkat kesukaran, dan daya pembeda butir soal.

\begin{tabular}{lclllll}
\hline Soal & Nilai Validitas & Kriteria & Nilai TK & Kriteria & Nilai DP & Kriteria \\
\hline X1 & 0,65 & valid & 0,26 & sukar & 0,27 & cukup \\
X2 & 0,75 & valid & 0,32 & sedang & 0,37 & cukup \\
X3 & 0,80 & valid & 0,45 & sedang & 0,45 & baik \\
X4 & 0,60 & valid & 0,68 & sedang & 0,55 & baik \\
X5 & 0,75 & valid & 0,20 & sukar & 0,45 & baik \\
X6 & 0,90 & valid & 0,36 & sedang & 0,67 & baik \\
X7 & 0,70 & valid & 0,42 & sedang & 0,23 & cukup \\
X8 & 0,80 & valid & 0,32 & sedang & 0,45 & baik \\
X9 & 0,60 & valid & 0,68 & sedang & 0,56 & baik \\
X10 & 0,75 & valid & 0,20 & sukar & 0,43 & baik \\
X11 & 0,65 & valid & 0,32 & sedang & 0,23 & cukup \\
X12 & 0,86 & valid & 0,50 & sedang & 0,68 & baik \\
X13 & 0,89 & valid & 0,29 & sedang & 0,50 & baik \\
X14 & 0,77 & valid & 0,60 & sedang & 0,67 & baik \\
X15 & 0,84 & valid & 0,32 & sedang & 0,46 & baik \\
X16 & 0,89 & valid & 0,35 & sedang & 0,54 & baik \\
X17 & 0,89 & valid & 0,56 & sedang & 0,35 & cukup \\
X18 & 0,77 & valid & 0,60 & sedang & 0,24 & cukup \\
X19 & 0,67 & valid & 0,65 & sedang & 0,48 & baik \\
\hline
\end{tabular}


Nilai validitas berdasarkan Tabel. 5 semuanya lebih dari 0,5 artinya seluruh butir soal valid dan instrumen valid. Adapun untuk Tingkat kesukaran butir soal semuanya sulit dan sedang. Hal ini wajar mengingat soal berbentuk HOTS memang bukan soal mudah dan rutin. Adapun daya pembedanya adalah baik dan cukup. Artinya instrumen ini dapat membedakan antara siswa yang bisa mengerjakan dengan siswa yang tidak bisa mengerjakan. Reliabilias instrumen dihitung dengan rumus Cronbach-Alpha dengan bantuan SPSS IBM 2.0. Adapun kriteria reliabilitas adalah nilai Cronbach-Alpha lebih dari 0,7 dikatakan instrumen dapat digunakan dan reliabel (Hayati \& Lailatussaadah, 2016). Adapun berdasarkan perhitungan tersebut nilai reliabilitas instrumen HOTS matematika siswa SMP kelas VII semester satu yang dikembangkan adalah 0,86. Nilai ini lebih dari 0,5 artinya instrumen reliabel.

Secara umum instrumen pengukur HOTS matematika bagi siswa SMP kelas VII semester satu dapat digunakan. Instrumen ini memuat indikator analisis, evaluasi, dan kreasi. Pendapat Arifin \& Retnawati (2017) menyatakan untuk membuat soal HOTS yang valid, reliabel, dan layak digunakan maka harus memuat kemampuan berpikir kritis dan kreatif. Tentu saja kemampuan berpikir kritis jelas termuat kedalam kemampuan analisis dan evaluasi. Lebih lanjut dinyatakan bahwa instrumen yang tepat tentu dapat benar-benar mengukur kemampuan HOTS siswa. Instrumen ini dapat digunakan untuk melatih dan membiasakan siswa untuk melakukan dan menghadapi soal-soal bentuk HOTS. Soal bentuk HOTS diperlukan sebagai upaya meningkatkan kemampuan HOTS siswa. Aktivitas siswa mengerjakan atau memecahkan suatu masalah dapat mendukung peningkatan kemampuan HOTS. Abdullah, Abidin,Ali (2015) menghasilkan suatu temuan bahwa aktivitas siswa dalam pemecahan masalah merupakan kegiatan yang dapat menghasilkan HOTS.

Lebih lanjut dikatakan bahwa instrumen HOTS yang tepat tidak lagi memuat soal-soal rutin. Hal ini wajar bahwa hasil tingkat kesukaran instrumen yang dikembangkan oleh peneliti adalah tingkat sulit dan sedang. Artinya soal-soal HOTS memang bukan jenis soal yang mudah dikerjakan. Biasanya soal-soal ritin hanya memuat indikator pengetahuan atau prosedural. Namun indikator ini tidak masuk dalam ranah kemampuan HOTS. (Pratama \& Retnawati, 2018) menyatakan bahwa dalam dimensi pengetahuan, tingkat pengetahuan mengenai fakta tidak termasuk dalam HOTS. Lebih lanjut dinyatakan bahwa tingkatan tugas dengan dinyatakan bahwa tingkatan tugas dengan karakter HOTS yaitu langkah pengerjaannya tidak bisa diprediksi, bukan soal rutin, memuat banyak solusi, membutuhkan usaha lebih dalam mengerjakannya. Adapun HOTS berdasarkan tingkatan kognitif yaitu analisis, evaluasi, dan kreasi.

Membahas mengenai HOTS tentu tidak sekadar membahas tingkat pengetahuan saja. Lebih jauh Pratama\&Retnawati (2018) menyatakan bahwa tugas-tugas untuk HOTS dapat diperdalam berdasarkan karakteristik tugas HOTS, dimensi kemamapuan, tingkat kognitif, dan tingkatan pengetahuan. Hasil penelitian ini menunjukkan skor rerata siswa adalah 71. Rerata ini hanya 1 poin di atas KKM. Hasil ini menunjukkan kemampuan HOTS siswa belum terlalu baik. Hasil ini sejalan dengan penelitian 
DOI: https://doi.org/10.24127/ajpm.v9i4.3162

(Arifin \& Retnawati, 2017) yang menyatakan skor HOTS siswa SMA kurang baik.

Kemampuan ini harus terus dilatih agar tidak terjadi kebingungan siswa dalam mengerjakan soal matematika yang tergolong berpikir tingkat tinggi. Ketika siswa diberikan soal yang brbeda dengan contoh dari guru maka mereka terlihat bingung untuk menyelesaikan soal tersebut (Yuni, Alghadari, \& Wulandari, 2019).

Dapat disimpulkan bahwa Soalsoal tipe HOTS yang membutuhkan pemikiran tingkat tinggi dapat melatih siswa berpikir dalam level analisis, evaluasi, dan mengkreasi sehingga soalsoal tersebut harus semakin dikembangkan dalam kurikulum 2013 agar dapat mendukung peningkatan kemampuan literasi matematika siswa (Suryapuspitarini, Wardono, \& Kartono, 2018).

\section{KESIMPULAN DAN SARAN}

Berdasarkan hasil penelitian dikembangkan instrumen pengukur HOTS matematika siswa SMP semester satu sebanyak 18 butir soal dengan indikator analisis, evaluasi, dan kreasi. Standar kompetensi mencakup bilangan, himpunan, aljabar, dan sistem persamaan linier dua variabel. Instrumen dinyatakan valid dan reliabel dengan tingkat kesukaran soal adalah sedang dan sulit, sedangkan daya pembeda soal adalah baik dan cukup. Adapun rerata siswa dalam menjawab soal instrumen pengukur HOTS adalah 71 (skala 0-100).

Penelitian ini dapat dijadikan salah satu bahan untuk mengukur kemampuan HOTS siswa SMP kelas VII. Penelitian ini dapat dikembangkan lebih lanjut untuk menganalisis pada level mana HOTS siswa SMP di Indonesia berada. Bagi guru dapat dijadikan salah satu referensi soal ulangan harian yang berbentuk HOTS untuk melatih aktivitas HOTS siswa.

\section{DAFTAR PUSTAKA}

Abdullah, A.H., Abidin, N. L. Z., \& Ali. M. (2015). Analysis of Students' Errors in Solving Higher Order Thinking Skill (HOTS) Problem for The Topic of Fraction. Journal Of Asian Social Science 11, 133142.

Arifin, Z., \& Retnawati, H. (2017). Pengembangan Instrumen Pengukur Higher Order Thinking Skills Matematika Siswa SMA Kelas X. Pythagoras: Jurnal Pendidikan Matematika , 12 (1), 98-108.

Branch, R. M. (2009). Instruktional Design: The ADDIE Approch. Springer. US.

Budiman, A., Jailani. (2014). Pengembangan Instrumen Asesmen Higher Order Thinking Skill (HOTS) Pada Mata Pelajaran Matematika Kelas VIII Semester 1. Jurnal Riset Pendidikan Matematika. 1(2), 139-151.

Hanifah, N. (2019). Pengembangan Instrumen Penilaian Higher Order Thinking Skill (HOTS) di Sekolah Dasar. Current Research in Education: Conference Series Journal, 1(1), 1-8.

Hayati, S., \& Lailatussaadah. (2016). Validitas Dan Reliabilitas Instrumen, Pengetahuan Pembelajaran Aktif, Kreatif, Menyenangkan (Pakem) Menggunakan Model Rasch. Jurnal Ilmiah DIDAKTIKA , 16 (2), 169179.

Kurniasi, E.R., Yopa., \& Karennisa, F. (2020). Analisi Soal Ulangan Harian Matematika Kelas IX SMP Negeri 1 Toboali. Jurnal Ilmu Pendidikan (JIP), 12(1), 4352 
Pratama, G, S., Retnawati, H. (2018). Urgency of Higher Order Thinking Skills (HOTS) Content Analysis in Mathematics Textbook. Journal of Physics, Conf. Series 1097, 1-8

Prayitno, B. A., Suciyati., \& Titikusumawati, E. (2018). Enhanching Student's Higher Order Thinking Skills In Science Through Insdtad Stategy.Journal Of Baltic Science Education, 17(6), 1046-1055.

Sa'idah, N., Yulistiani, H. D., \& Megawati, E. (2019). Analisis Instrumen Tes Higher Order Thinking Matematika SMP. Jurnal Pendidikan Matematika, 13 (1), 41-54.

Suryapuspitarini, Wardono, \& Kartono. (2018). Analisis Soal-Soal Matematika Tipe Higher Order Thinking Skill (HOTS) pada Kurikulum 2013 untuk Mendukung Kemampuan Literasi Siswa. Jurnal Prisma: Prosiding Seminar Nasional, 1(1), 876-884
Tanujaya, B., Mumu,J., \& Margono, G. (2017). The Relationship Between Higher Order Thinking Skills and Academic Performance of A Student in Mathematics Instruction. The Journal of International Education Studies, 10(11), 78-88.

TIMSS. (2015). International Results in Mathematics, TIMSS\&PIRLS International Study Centre Lynch School Of Education, Boston Collage.

Yuni, Y., Alghadari, F., \& Wulandari, A. Gender Reviewed Mathematical Intuition at $7^{\text {th }}$ Grade Students Through OpenEnded Based-Inquiry Learning. Journal Of Physics, Conf. Series $1315,1-7$

Zaini, M. (2015). Hasil Belajar dan Keterampilan Berpikir Tingkat Tinggi Siswa SMA pada Pembelajaran Biologi Menggunakan Model Pembelajaran Berdasarkan Masalah. Jurnal Pendidikan Biologi, 20(207), 3443. 